\title{
Early outcomes of tapering jejunoplasty by antimesenteric seromuscular stripping and mucosal inversion for proximal jejunal atresia
}

\author{
Mahmoud Marei Marei ${ }^{1,2^{*}}$ (D), Mohamed Hamed Abouelfadl ${ }^{1}$, Ahmed Arafa Elsayed Rawwash ${ }^{1}$, \\ Hamed Mahmoud Seleim ${ }^{1,3}$, Wesam Mohamed Mahmoud ${ }^{1}$, Tamer Yassin Mohamed Yassin ${ }^{1}$ and \\ Gamal Hassan El-Tagy ${ }^{1}$
}

\begin{abstract}
Background: High jejunal atresia is associated with significant dilatation of the proximal segment. This poses two problems: (a) calibre discrepancy with the distal unused segment and (b) hypomotility causing stasis. Tapering jejunoplasty/enteroplasty could offer a practical solution in selected cases, leading to early establishment of feeds. This work aims to evaluate the outcome of tapering jejunoplasty including its effect on establishing enteral feeding in neonates with proximal jejunal atresia.

Results: Twenty-two neonates with jejunal atresia (types I, II and IIIa) were reviewed. Cases with multiple atresia, apple-peel variant and meconium ileus were excluded. The included cases fell retrospectively into two groups: group A (13 cases) - very proximal atresia and significant dilatation and group B (9 cases) - mid/distal jejunal atresia. For group A, we excised only the distal tip of the dilated bowel and stripped a seromuscular triangle up to the duodenojejunal flexure and inverted the mucosa along the antimesenteric border, followed by an end-to-oblique anastomosis. For group B, we performed a standard excision of a short proximal segment and an end-to-oblique anastomosis. There was no significant difference in the gestation age or birth weight between both groups. The mean operative time was 90 min for group A and 60 min for group B. The duration until full enteral feeds became tolerated, and parenteral nutrition was weaned accordingly was shorter in group A (mean 10.8 days) as compared to group B (mean 14.5 days), $p=0.045$.
\end{abstract}

Conclusion: Tapering jejunoplasty by seromuscular stripping and mucosal inversion facilitates early establishment of feeds in proximal jejunal atresia.

Keywords: Jejunal atresia, Tapering jejunoplasty, Enteroplasty, Hypomotility, Dysmotility, Neonatal surgery

\section{Mini abstract}

The dilated proximal segment in jejunal atresia poses two problems: calibre discrepancy and hypomotility. Tapering jejunoplasty by seromuscular stripping and mucosal inversion achieves a good outcome and leads to a comparatively early establishment of feeds.

\footnotetext{
* Correspondence: m.marei@kasralainy.edu.eg; m.marei@nhs.net ${ }^{1}$ Department of Surgery, Pediatric and Neonatal Surgery Unit, Cairo University Specialized Pediatric Hospital (CUSPH), Faculty of Medicine, Cairo University, Cairo, Egypt

Full list of author information is available at the end of the article
}

\section{Background}

Jejunoileal atresia is the most common congenital anomaly of the small intestine and represents an important cause of neonatal intestinal obstruction. Its incidence is three cases per 10,000 live births [1,2]. Proximal (high) jejunal atresia is more frequent (54\%) than middle and distal jejunal forms (45\%), excluding multiple atresia [3].

With at least 1,300,00 live births per year in Egypt, about 400-500 cases of jejunoileal atresia are being born yearly $[4,5]$. These cases are managed within 12 university pediatric surgical public-funded centres [6]. For 
these reasons, any possible modification of the surgical technique to establish earlier enteral feeds and earlier discharge becomes a matter of exceeding importance to the individual patient and the system.

Surgery for jejunoileal atresia evolved progressively in the second half of the last century. Nixon in 1955 resected the dilated bowel up to the ligament of Treitz, which was possibly performed if an adequate proximal and distal length of the intestine is present, followed by an end-to-oblique anastomosis and showed an improved survival rate [7-9]. In 1973, Howard and Othersen described a tapering jejunoplasty [10]. Tapering of the dilated part on the antimesenteric border reportedly was performed using a stapler or hand sewn with end-to-end anastomosis [11, 12]. De Lorimier and Harrison brought to attention that intestinal imbrication reduces the luminal diameter and restores function while preserving the mucosal surface area [13, 14], which was subsequently reported for megaduodenum as well [15]. This concept evolved into seromuscular stripping of an ellipse of the proximal dilated bowel, as described by Kimura et al (1996) [16], aiming to improve the motility of the dysfunctional proximal bowel, which is the basis for our technique.

The surgical conundrum is that in proximal jejunal atresia, within $20 \mathrm{~cm}$ from the ligament of Treitz, resection to an adequate calibre is occasionally not possible without mobilisation of the duodenojejunal (DI) flexure and duodenal derotation, which is challenging and may risk the superior mesenteric vascular pedicle and the fraught biliary structures. The proposed solution in this report is excision of only the distal tip of the dilated bowel, stripping a triangle of seromuscular layer up to the DJ flexure and completing a hand-sewn inversion of mucosa along the antimesenteric border, without duodenal derotation, followed by a single-layer end-tooblique anastomosis.

The aim of this work is to study the effect of tapering enteroplasty benchmarked to simple resection and anastomosis on the postoperative establishment of enteral feeding, traditionally known to be hampered by the disturbed intestinal transit in cases of proximal jejunal atresia.

\section{Methods}

This study is a retrospective review of a case series. There was no randomisation. The employed decisionmaking and group-allocation is the protocol the authors would normally follow in managing proximal jejunal atresia.

Neonates admitted to the neonatal surgical unit of a tertiary university centre, between September 2014 and January 2017, were reviewed. Approval of the departmental scientific and research committee was obtained for data collection and review. Twenty-two neonates with jejunal atresia (types I, II and IIIa) were included. Cases with multiple atresia, apple-peel variant and meconium ileus were excluded from this analysis and report, to avoid their additional confounding anatomical and physiological malabsorptive effect. Those included were analysed into two groups: group A-proximal atresia (distance $<20 \mathrm{~cm}$ from DJ flexure) which was always accompanied with significant dilatation, extending back to the DJ flexure and group $\mathrm{B}$-more distal jejunal atresia (distance $>20 \mathrm{~cm}$ from DJ flexure).

A full-detailed antenatal and post-natal history was taken for each case to detect any comorbidities or risk factors. Clinical examination was done to identify any associated anomalies. All neonates presenting with bilious vomiting, delayed or failure of passage of meconium, mild to moderate abdominal distension or abnormal Xray films showing distended proximal intestinal loops, triple bubble sign or air-fluid levels were considered. All cases received the initial resuscitation in the form of intravenous fluids, nasogastric (NG) suction with fluid replacement and a vitamin $\mathrm{K}$ injection. First-line antibiotics were administered as necessary.

Group A comprises 13 cases of proximal jejunal atresia, for which an excision of the distal tip of the dilated bowel was done followed by stripping a triangle of seromuscular layer up to the DJ flexure. We then completed a hand-sewn continuous or interrupted inversion of the mucosa along the ante-mesenteric border, without duodenal derotation. At the edge, a single-layer end-tooblique anastomosis was done. This was our interventional group (Figs. 1, 2, 3, and 4).

Group B included 9 cases of distal jejunal atresia, for which the gold-standard excision of a short proximal segment and a single-layer end-to-oblique anastomosis was done. This was our control group.

\section{Operative description}

In proximal jejunal atresia (group A), a $\mathrm{V}$-shaped antimesenteric seromuscular stripping (Fig. $1 \mathrm{a}-\mathrm{c}$ ) while preserving the submucosa, and inversion tapering was done aiming to preserve the maximum mucosal surface area for absorption (Fig. 2). The apex of the $\mathrm{V}$ was proximal, and its base was at the cut-edge of the jejunum. The inversion employed interrupted or continuous Vicryl 5/0 or 6/0 (Fig. 3).

In mid/distal jejunal atresia (group B), the blind bulbous end of the proximal intestine was always resected, and the excision was extended back to healthy-looking non-hypertrophied bowel, if the bowel length and the distance from the DJ flexure permitted. However, the length of proximal excision was not uniform and had to respect retaining a sufficient segment to make an anastomosis with it, comfortably away from the DJ flexure. 

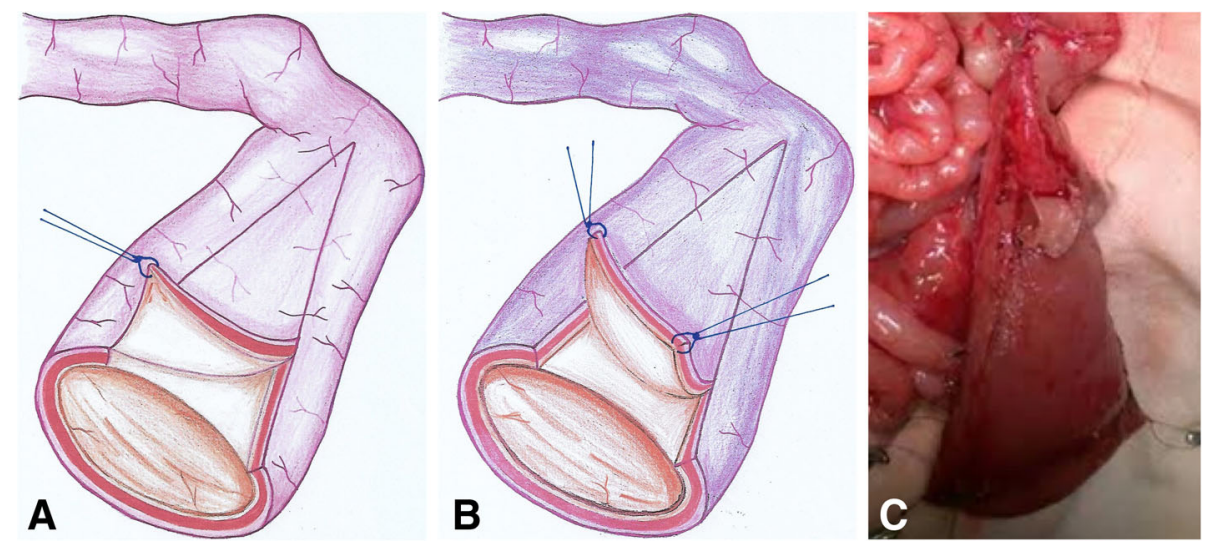

Fig. 1 Seromuscular layer stripping (includes a-c). a Seromuscular layer stripping started from distal to proximal. b Seromuscular layer stripping proceeding from distal to proximal. c Seromuscular layer stripping proceeding from proximal to distal

To distend the distal segment and slightly reduce size discrepancy, we instilled $0.9 \% \mathrm{NaCl}$ solution with a 24 gauge cannula through a purse-string suture into a clamped distal pouch. The proximal intestine was transected at a right angle to maximise its vascularity, whereas the distal bowel was transected obliquely with the antimesenteric border spatulated to partially equalise the size of the openings on both sides for the anastomosis.

A single-layer end-to-back (end-to-oblique) anastomosis was performed. The mesenteric gap was then approximated with Vicryl 6/0 absorbable sutures. Patency of the anastomosis was tested by milking intestinal air through it (Fig. 4). The intestinal segment was then moistened and washed with warm saline solution, returned to the abdominal cavity and the abdominal wound was closed in layers.

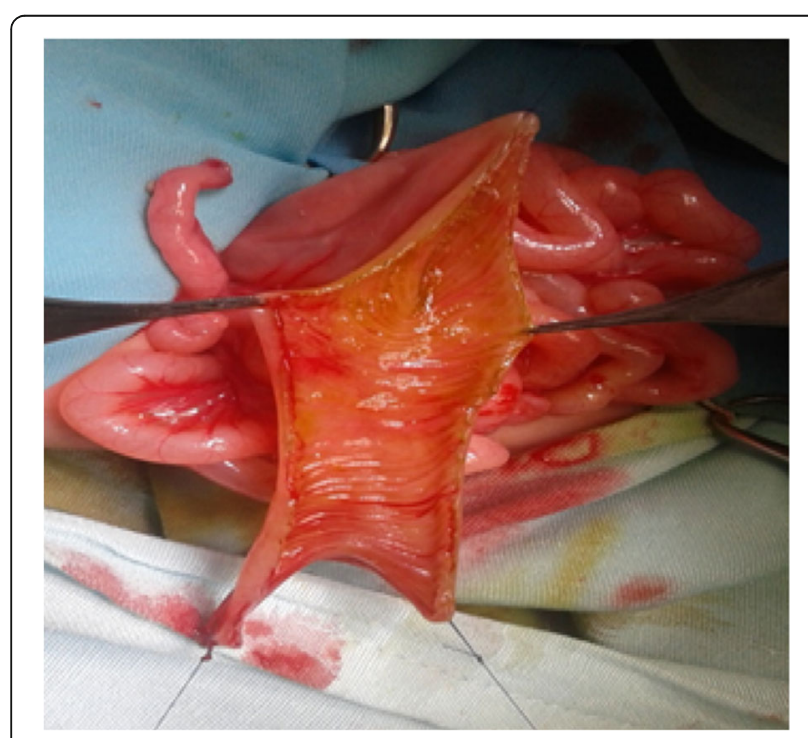

Fig. 2 Seromuscular stripping completed

\section{Post-operative care}

A central intravenous catheter was inserted at the time of operation in all cases due to the expected prolonged ileus and need for parenteral nutrition. Parenteral nutrition was started on the second postoperative day. Low intermittent suction was maintained on an orogastric (OG) or nasogastric (NG) tube until meconium or changing stools were passed and the drainage from the OG/NG was less than 1 $\mathrm{mL} / \mathrm{kg} / \mathrm{h}(20 \mathrm{~mL} / \mathrm{kg} /$ day $)$ and became clear. Feeding was advanced slowly by mouth or OG/NG tube. As intestinal function was regained, the patient was progressively weaned from parenteral to enteral nutrition until the full nutritional requirements were enterally obtained. A postoperative gastrografin follow-through was done if tolerance to feeds was

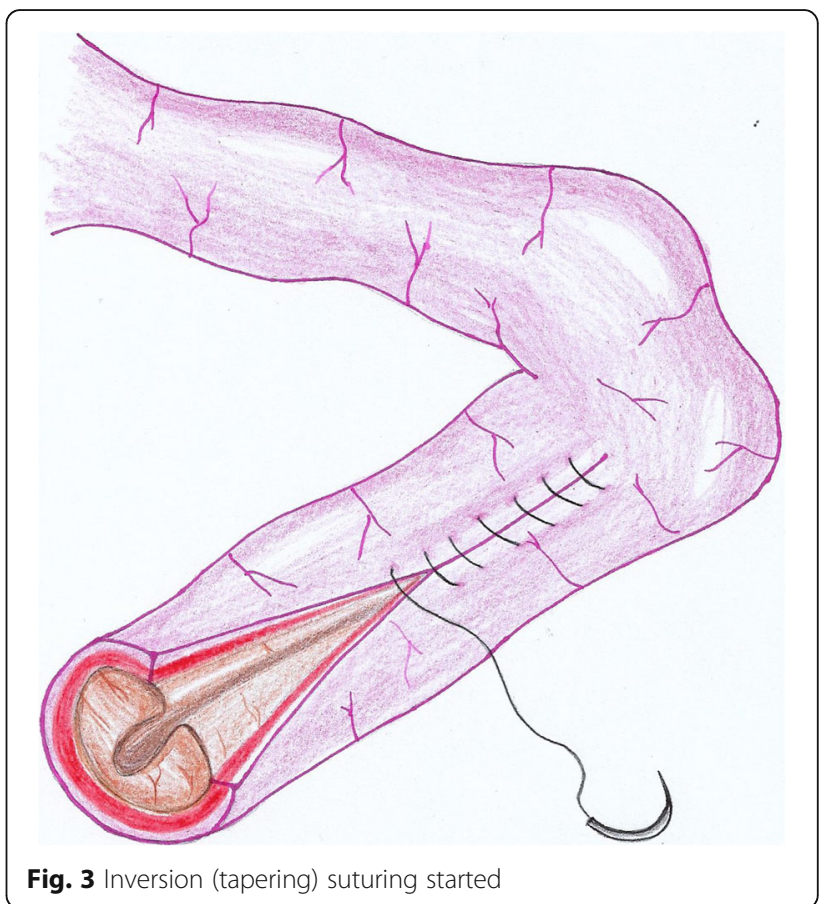




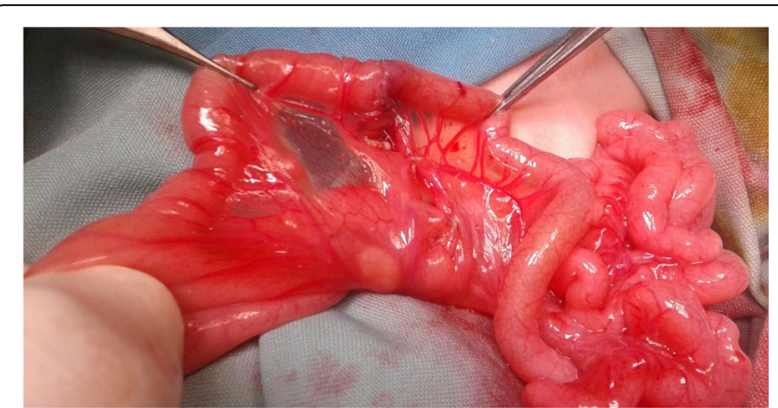

Fig. 4 Tapering and anastomosis completed

delayed (beyond 10 days), or in the presence of upper abdominal distension, in order to exclude anastomotic problems. A more gradual and trophic enteric feeding was pursued in those that did not directly accept enteral (oral/ OG/NG) feeding. The standard metabolic surveillance of all patients was done throughout.

We studied the case notes for all procedure-related and intestinal dysfunction-related postoperative difficulties as early and delayed intolerance to feeds, high NG/OG aspirates and/or vomiting, anastomotic leak and early anastomotic strictures. We analysed various parameters across both groups, gestational age, birth weight, age at presentation, age at surgery and days to establish full enteral feeding of $150 \mathrm{~mL} / \mathrm{kg} /$ day and days to discharge.

\section{Statistical analysis}

The Shapiro-Wilk and Kolmogorov-Smirnov test were utilised to assess the normality of distribution for different variables. Statistical analysis was done on nonparametric basis. Accordingly, comparison between different variables in the two studied groups was performed using the Mann-Whitney test. Comparison between categorical variables was performed using chi-square test (when valid) or Fisher exact test instead. Data are expressed as median \pm range or interquartile range $(\mathrm{IQR})$, mean \pm standard deviation (SD) or number percentage. $p$ value $\leq 0.05$ was considered significant.

\section{Results}

Thirteen cases had the studied procedure performed: seromuscular stripping and mucosal inversion (group A) and nine cases fell in the comparison arm (group B), where excision of a short proximal segment and a single-layered end-to-oblique anastomosis was done.

There was no significant difference in the birth weight's mean \pm SD between both groups. In group A, this was $3.08 \pm 0.28 \mathrm{~kg}$, and in group B, it was $3.11 \pm 0.6$ $\mathrm{kg}(p=0.804)$. The mean gestation age for the whole cohort was 37.8 weeks (IQR 37.5-38). Both groups appeared similar for gestation age, and there was no statistical difference on comparison: 37.9 weeks (IQR
37.5-38) in group A versus 37.6 weeks (IQR 36.5-38) in group B $(p=0.356)$. Interestingly, group B had two cases (22\%) with a gestation age of 34-36 weeks as compared to none in group A (all were 36+ weeks), which was not statistically significant $(p=0.075)$.

The median age at presentation was 1 day less in group A, 3 days old (range 2-6), than in group B, 4 days old (range $2-8$ ), $p=0.004$. The mean age at surgery was also 1 day less in group A, 4 days old (range 4-8), than in group B, 5 days old (range $3-10$ ), $p=0.027$. The mean \pm SD operative time was $90 \pm 19.5$ min for group A and $60 \pm 9.4 \mathrm{~min}$ for group B $(p=0.01)$. Table 1 outlines the characteristics and possible confounders across both groups.

The duration (mean $\pm \mathrm{SD}$ ) until $150 \mathrm{~mL} / \mathrm{kg} /$ day of enteral feeds became tolerated, and parenteral nutrition was weaned was shorter in group A (10.8 \pm 3.5 days $)$ compared to group B (14.5 \pm 5.1 days), $p=0.045$. For the same parameter, the median was 10 days (range $7-$ 21 ) in group A versus 14 days (range 10-21) in group B. The days until discharge reflected this and were $12.15 \pm$ 3.5 days in group A versus $16 \pm 5.05$ days in group B ( $p$ $=0.038$ ). The median follow-up was 1.8 years (IQR 1.33.2 years). There was no mortality in either group. Table 2 outlines the outcomes, post-operative difficulties and complications across both groups.

In this cohort, we had one case which had an anastomotic leak in the tapering jejunoplasty (enteroplasty) group, which was early detected and re-operated upon, on the seventh post-operative day. In the simple resection/oblique anastomosis group, one patient had an early stricture that was detected on a contrast study for delayed feeding on the 11th post-operative day. Both patients achieved full enteral feeding at 21 days from the initial surgery.

\section{Discussion}

The Young-Laplace equation (Laplace's law) governs pressure in balloon-like chambers with tension in the wall. This tells us that at a fixed tension in the wall (analogous to the contractility and inherent elasticity of the muscularis or muscle coat), the pressure drops significantly as the dilatation of the ectatic segment increases. Reciprocally, the smaller the radius, the higher the pressure and the more propulsive the bowel could be by building pressure across the anastomosis [17].

Even more importantly, Hagen-Poiseuille equation governs the flow of fluid in a tube: $\Delta P=8 \mu L Q / \Pi R^{4}$, where $\Delta P$ is the pressure difference between the two ends, $\mathrm{L}$ is the length of pipe, $\mu$ is the dynamic viscosity, $Q$ is the volumetric flow rate and $R$ is the pipe radius. This unequivocally shows that the change in pressure is inversely (negatively) proportionate to the fourth power 
Table 1 Characteristics of both groups

\begin{tabular}{|c|c|c|c|}
\hline Characteristics of both groups (confounding factors) & Group A $(n=13)$ & Groups B $(n=27)$ & $p$ value \\
\hline $\begin{array}{l}\text { Gestational age in weeks } \\
\text { Mean } \pm \text { SD } \\
\text { Median (IQR) }\end{array}$ & $\begin{array}{l}37.61 \pm 1.34 \text { weeks } \\
37.9 \text { (IQR } 37.5-38) \text { weeks }\end{array}$ & $\begin{array}{l}37.92 \pm 0.4 \text { weeks } \\
37.6 \text { (IQR 36.5-38) weeks }\end{array}$ & 0.356 \\
\hline $\begin{array}{l}\text { Gestational age (maturity/prematurity) } \\
\text { Full term ( }>36 \text { weeks) } \\
\text { Preterm (<36 weeks) }\end{array}$ & $\begin{array}{l}13(100.0 \%) \text { cases } \\
0(0 \%)\end{array}$ & $\begin{array}{l}9(77.8 \%) \text { cases } \\
2(22.2 \%) \text { cases }\end{array}$ & 0.075 \\
\hline Birth weight (mean $\pm \mathrm{SD}$ ) & $3.08 \pm 0.28 \mathrm{~kg}$ & $3.11 \pm 0.6 \mathrm{~kg}$ & 0.804 \\
\hline Male to female distribution & $9: 4$ & $6: 3$ & 0.899 \\
\hline $\begin{array}{l}\text { Age at presentation } \\
\text { Median (range) }\end{array}$ & 3 days ( $2-6$ days) & 4 days ( $2-8$ days) & 0.004 \\
\hline $\begin{array}{l}\text { Age at surgery } \\
\text { Median (range) }\end{array}$ & 4 days ( $4-8$ days) & 5 days ( $3-10$ days) & 0.027 \\
\hline
\end{tabular}

of the tube radius, highlighting the importance of reducing the diameter of the ectatic segment [18].

Although their study was on duodenal atresia, Takahashi et al. interestingly studied the contraction profile with manometry proximal to the anastomosis and demonstrated low contraction amplitudes in dilated segments, in seven newborns, as early as 2 weeks after surgery. They excluded confounders by multivariate analysis and concluded that the low contraction amplitude of the dilated bowel was the main pathophysiological feature [19].

From a technical perspective, to avoid an obstruction by the keel of the inverted mucosa at the anastomotic edge, the mucosa/submucosa to be folded should be kept to less than half of the circumference at the edge; otherwise, trimming of the inverted mucosa at the proximal end is advisable [20]. This inverted mucosa may preserve the absorptive capacity and offers the advantage of a lower risk of anastomotic leakage through the plication line as compared to excision by a stapling device. In our series, the single case of leak in group A was at the anastomotic line and not along the tapering enteroplasty suture line. As it is stripped off the seromuscular layer, this keel becomes much less bulky than in imbrication without stripping.

There are reports of a similar approach for proximal jejunal atresia in a few series $[16,20,21]$. In one report of 11 newborns, they achieved full feedings at $12.7 \pm 1.8$ days after the operation, and in another, full feeds were achieved around the ninth to tenth day postoperatively in three babies $[20,21]$. This is generally similar and comparable to our results, where feeds were established at $10.8 \pm 3.5$ days.

The alternative techniques, aiming at a similar goal include (a) imbrication of the dilated part, without stripping the mucosa on the antimesenteric border, either using a stapler or hand-sewn [13], and (b) derotation of the dilated duodenum and jejunum after takedown of the ligament of Treitz [22, 23].

The imbrication caries the issue of the bulkiness of the inverted mass, possibly causing obstruction at the delicate anastomotic site, and there are reports of breakdown and recurrent dilatation [13]. The derotation is a lengthier and technically demanding operation, necessitating extreme carefulness with the superior mesenteric vascular pedicle and the biliary structures. However, it is anatomically sound and appealing when a megaduodenum needs to be addressed as it allows a duodenoplasty as well and achieves a dependent duodenojejunostomy.

One of the disadvantages of our technique is the longer operative time. Hypothetically, it may be difficult to entirely eliminate the risk of anastomotic leakage; and theoretically, there is an unpredictable absorptive capacity of the stripped area. However, it obviously reduces the luminal diameter and helps in restoration of function by improving peristalsis, an objective that has been

Table 2 Postoperative difficulties and complications across both groups

\begin{tabular}{|c|c|c|c|}
\hline Postoperative difficulties and complications compared across both groups & Group A $(n=13)$ & Group B $(n=9)$ & $p$ value \\
\hline Stenosis & $0(0 \%)$ & $1(11.1 \%)$ & 0.409 \\
\hline Anastomotic leak & $1(7.7 \%)$ & $0(0 \%)$ & 0.591 \\
\hline Early transient bowel dysfunction and high nasogastric aspirates & $1(7.7 \%)$ & $4(44.4 \%)$ & 0.043 \\
\hline Delayed feeding tolerance (need for PN beyond 14 days) & $0(0 \%)$ & $3(33.3 \%)$ & 0.054 \\
\hline Failure to thrive (poor weight gain during infancy) & $1(7.7 \%)$ & $3(33.3 \%)$ & 0.125 \\
\hline None of the above complications & $10(76.9 \%)$ & $2(22.2 \%)$ & 0.027 \\
\hline
\end{tabular}


stressed as crucial by many authors [10, 12, 13]. Until this report, we limited using the tapering to only the very proximal atresia, but as a future direction, we would consider resecting less bowel and tapering what is left proximally, even in mid/distal jejunal atresia.

A valid critical question is why when the dilated bowel was excised, longer recovery was noted than when it was tapered? The explanation, in our view, is that tapering can be extended more proximally than excision, leaving less dilated/ectatic bowel. Excision of the ectatic bowel segment could never be consistently complete, leaving only healthy bowel in every case. It must differ from one case to the other, in order to technically allow for an anastomosis a little distant from the DJ flexure. Additionally, we are cognisant of the major interplay between the gestation age (prematurity), birth weight, age at presentation (within the circumstances of our referral system), pre-operative sepsis and dehydration and the quality/vascularity of the residual bowel which could have all contributed to the difference between both groups. One view could be to read this article as two separate case series, put side-to-side, to show the outcomes of tapering jejunoplasty, in the context of our general neonatal surgical care and outcomes, when it comes to the jejunoileal atresia domain.

The main limitation of this study is being retrospective and thus observational. The ideal study would be to randomise all neonates with proximal jejunal atresia into having the studied operation versus a gold standard, assuming it is possible to define one, and then to analyse both groups. This would be methodologically more robust but indeed would attract a set of challenging issues around randomisation and its pertinent ethical considerations. On the other hand, without prospective randomisation, it is difficult to completely isolate confounding factors. Both groups were comparable to a reasonable extent, albeit not identical. The number of cases (statistical power) allowed the key findings to be proven statistically valid. Having stated the limitations, this series remains the largest reported to date for this technical modification.

\section{Conclusion}

We found that tapering enteroplasty is feasible and beneficial for cases with proximal jejunal atresia with ectatic dilatation extending back to the duodenojejunal flexure. It is a safe technique, and despite being a lengthier operation, enteral feeding could be established early. It is an optional modification within the neonatal surgical armamentaria, which is suitable for a selected group of challenging cases.

\section{Abbreviations}

DJ: Duodenojejunal flexure; IQR: Interquartile range; NG: Nasogastric; OR: Orogastric; SD: Standard deviation

\section{Acknowledgements}

We are considerably grateful to Dr Tarek Diab, PhD, for his valued help with the statistical analysis in this work. We would also like to express our immense gratitude to Ms Amal Sharaf, MRCS, for her informative operative drawings and diagrammatic illustrations.

\section{Authors' contributions}

GHE and TYMY have overseen and supervised the study. MMM, MHA, AAER, HMS and WMM performed the surgical operations. HMS, MMM and AAER conceptualised the study design and basis. AAER and HMS contributed to the literature review and operative photographs. MHA, MMM and AAER contributed to the data collection, verification and scrutiny. MMM drafted and produced the manuscript, arranged and supervised the statistical analysis and operative illustrations, then responded to the peer reviewers. All authors shared the critique and revision of the manuscript. All authors have read and finally approved the manuscript.

\section{Funding}

There are no funding sources to declare. There are no sources of support (grants, equipment and drugs) to declare.

\section{Availability of data and materials}

The data and material for this study are available and stored confidentially.

\section{Ethics approval and consent to participate}

This study is a retrospective review and is neither prospective nor experimental. A research ethical approval was not applicable; however, approval for the data collection and review for the purpose of this study was obtained from the research and scientific committee of the Department of Pediatric Surgery at Cairo University Specialised Pediatric Hospital in January 2017. The consent to participate is not applicable, as patients received non-experimental surgical care. The study is observational to gather specific information about an approved procedure. However, consent for any clinically indicated surgical procedure or medical intervention followed the standard informed and written documentation.

\section{Consent for publication}

Not applicable, as there are no patient-identifiable data published herein.

\section{Competing interests}

The authors declare that they have no competing interests.

\section{Author details}

${ }^{1}$ Department of Surgery, Pediatric and Neonatal Surgery Unit, Cairo University Specialized Pediatric Hospital (CUSPH), Faculty of Medicine, Cairo University, Cairo, Egypt. ${ }^{2}$ The Royal Manchester Children's Hospital and Manchester Royal Infirmary, Manchester University NHS Foundation Trust, Oxford Road, M13 9WL, Manchester, England, UK. ${ }^{3}$ Department of Pediatric Surgery, Tanta University Hospital, Faculty of Medicine, Tanta University, Tanta, Egypt.

Received: 4 June 2019 Accepted: 30 August 2019

Published online: 09 October 2019

\section{References}

1. Waldhausen JH, Sawin RS (1997 Sep) Improved long-term outcome for patients with jejunoileal apple peel atresia. J Pediatr Surg 32(9):1307-1309. https://doi.org/10.1016/s0022-3468(97)90308-0.

2. Stollman $\mathrm{TH}$, de Blaauw I, Wijnen MH, van der Staak FH, Rieu PN, Draaisma JM, Wijnen RM (2009 Jan) Decreased mortality but increased morbidity in neonates with jejunoileal atresia; a study of 114 cases over a 34-year period. J Pediatr Surg 44(1):217-221. https://doi.org/10.1016/j.jpedsurg.2008.10.043

3. Merkel M (2011) Jejunal atresia. Postoperative outcome after small bowel atresia. Dissertation (Diplomarbeit: Mat.Nr.: 0633182), Medizinischen Universität Graz. Unter der Anleitung von Univ. Prof. Dr. M.E. Höllwarth. 2011;3.1.4.2. pp.46.

4. The World Bank (2018). Data by Country/Egypt, Arab Rep. Country Profile. https://databank.worldbank.org/data/views/reports/reportwidget. aspx?Report Name $=$ CountryProfile\&ld $=b 450 f d 57 \&$ tbar $=y \& d d=y \& i n f=n \& z m=$ n\&country=EGY. Accessed 30 Sept 2019. 
5. Egypt Demographic and Health Issues Survey 2015. Ministry of Health and Population, Cairo, Egypt. El-Zanaty and Associates, Cairo, Egypt and The DHS Program ICF International, Rockville, Maryland, USA, October 2015. https:// dhsprogram.com/publications/publication-FR313-DHS-Final-Reports.cfm

6. Elhalaby EA, Uba FA, Borgstein ES, Rode H, Millar AJW (2012) Training and practice of pediatric surgery in Africa: past, present, and future. Seminars in Pediatric Surgery 21(2):103-110. https://doi.org/10.1053/j.sempedsurg.2012. 01.002 .

7. Nixon HH (1955) Intestinal obstruction in the newborn. Arch Dis Child 30:13-22 https://doi.org/10.1136/adc.30.149.13.

8. Nixon HH, Tawes R (1971 Jan) Etiology and treatment of small intestinal atresia: analysis of a series of 127 jejunoileal atresias and comparison with 62 duodenal atresias. Surgery 69(1):41-51.

9. Louw JH (1966 Apr-Jun) Congenital atresia and stenosis of the small intestine. The case for resection and primary end-to-end anastomosis. S Afr J Surg 4(2):57-64.

10. Howard ER, Othersen HB Jr (1973 Oct) Proximal jejunoplasty in the treatment of jejunal atresia. J Pediatr Surg 8(5):685-690. https://doi.org/10 1016/0022-3468(73)90407-7.

11. Grosfeld JL, Ballantine TV, Shoemaker R (1979 Jun) Operative management of intestinal atresia and stenosis based on pathologic findings. J Pediatr Surg 14(3):368-375. https://doi.org/10.1016/s0022-3468(79)80502-3.

12. Thomas CG Jr, Carter JM (1974 May) Small intestinal atresia: the critical role of a functioning anastomosis. Ann Surg 179(5):663-670.

13. De Lorimier AA, Harrison MR (1983 Dec) Intestinal plication in the treatment of atresia. J Pediatr Surg 18(6):734-737. https://doi.org/10.1016/s00223468(83)80014-1.

14. De Lorimier AA, Norman DA, Goodling CA, Preger L (1973 Oct) A model for the cinefluoroscopic and manometric study of chronic intestinal obstruction. J Pediatr Surg 8(5):785-791. https://doi.org/10.1016/00223468(73)90422-3.

15. Adzick NS, Harrison MR, de Lorimier AA (1986 Apr) Tapering duodenoplasty for megaduodenum associated with duodenal atresia. J Pediatr Surg 21(4):311-312 https:/doi.org/10.1016/s0022-3468(86)80191-9.

16. Kimura K, Perdzynski W, Soper RT (1996 Oct) Elliptical seromuscular resection for tapering the proximal dilated bowel in duodenal or jejunal atresia. J Pediatr Surg 31(10):1405-1406. https://doi.org/10.1016/s00223468(96)90839-8.

17. Valentinuzzi ME, Kohen AK (2011 July-Aug) Laplace's Law: What It Is About, Where It Comes from and How It is Often Applied in Physiology. IEEE Pulse [Retrospectroscope] 2(4):74-84. https://doi.org/10.1109/MPUL.2011.942054.

18. Farag A (1998) Use of the Hagen-Poiseuille law: a new mathematical approach for the integration and evaluation of anorectal physiological testing in patients with faecal incontinence and pelvic dyschezia and in normal controls. Eur Surg Res 30(4):279-289. https://doi.org/10.1159/000008588.

19. Takahashi A, Tomomasa T, Suzuki N, Kuroiwa M, Ikeda H, Morikawa A, Matsuyama S, Tsuchida Y (1997 Aug) The relationship between disturbed transit and dilated bowel, and manometric findings of dilated bowel in patients with duodenal atresia and stenosis. J Pediatr Surg 32(8):1157-1160. https://doi.org/10.1016/s0022-3468(97)90674-6.

20. Solmaz B, Karakaya E, Hakgüder G, Ates O, Olguner M, Akgür FM (2008) Seromuscular stripping and plication technique for the treatment of the proximal jejunal atresia. Journal of the Turkish Association of Pediatric Surgeons and The Society for Pediatric Urology in Turkey. Çocuk Cerrahisi Dergisi 22(3):100-103.

21. Kizilcan F, Tanyel FC, Hiçsönmez A, Büyükpamukçu N (1991 May) Modified plication technique for the treatment of intestinal atresia. Pediatr Surg Int 6(3):233-234. https://doi.org/10.1007/BF00176079.

22. Kling $\mathrm{K}$, Applebaum H, Dunn J, Buchmiller T, Atkinson J. A novel technique for correction of intestinal atresia at the ligament of Treitz. J Pediatr Surg 2000 Feb; 35(2):353-355; discussion 356. https://doi.org/10.1016/s0022-3468(00)90039-3.

23. Luo CC, Ming YC, Chao HC, Chu SM (2010 Oct) Duodenal derotation and extent tapering jejunoplasty as primary repair for neonates with high jejunal atresia. Pediatr Neonatol 51(5):269-272. https://doi.org/10.1016/S1875-9572(10)60052-6

\section{Publisher's Note}

Springer Nature remains neutral with regard to jurisdictional claims in published maps and institutional affiliations.

\section{Submit your manuscript to a SpringerOpen ${ }^{\circ}$ journal and benefit from:}

- Convenient online submission

- Rigorous peer review

- Open access: articles freely available online

- High visibility within the field

- Retaining the copyright to your article

Submit your next manuscript at $\boldsymbol{\nabla}$ springeropen.com 